\title{
EL CARÁCTER ESPECULATIVO DE LA IUSTEORÍA PERIFÉRICA*
}

Leonardo Cely**

Fecha de recibido: 23 de febrero de 2014.

Fecha de aprobado: 8 de agosto de 2014.

Artículo de reflexión

Forma de citación: Cely, L. (2014). El carácter especulativo de la iusteoría periférica. Revista Prolegómenos. Derechos y Valores, 17, 34, 33-41.

\section{Resumen}

Este artículo analiza la relación entre "sitios de producción" y "sitios recepción", de la teoría jurídica propuesta por el profesor Diego López (ent la Teoría impura del derecho), a través del concepto de "representación" de Gadamer en Verdad y método, para mostrar el potencial teórico (y la relevancia) que tiene la iusteoría periférica en la lectura transnacional del pensamiento jurídico. Primero, se planteará, el vínculo entre "sitios de producción" y "sitios de recepción" en la teoría transnacional del derecho que desarrolla López. Segundo, se realizará una exposición del concepto de "representación" de Gadamer para proponer lo que él denomina el "carácter especulativo del lenguaje". Finalmente, se presentará, a partir de lo anterior, lo que se designa como el "carácter especulativo de la iusteoría de periferia" y se expondrán unas conclusiones generales.

\section{Palabras clave:}

Sitios de producción, teoría transnacional del derecho, representación, hermenéutica, Diego López, Gadamer.

\section{SPECULATIVE CHARACTER OF PERIPHERAL IUSTHEORY}

\begin{abstract}
This article analyzes the relationship between "production places" and "reception places" of the legal theory proposed by Professor Diego Lopez (in Impure Theory of Law), through Gadamer's concept of "representation" in Truth and Method, in order to show the theoretical potential (and relevance) that peripheral iustheory has in the transnational reading of legal thought. First, the bond between "production places" and "reception places" in the transnational theory of law developed by Lopez will be considered. Second, an exposition of Gadamer's concept of "representation" will be carried out to propose what he names "speculative caracter of language".
\end{abstract}

Artículo de reflexión resultado del curso internacional "Investigación Jurídica y Socio-Jurídica para el aula" de la Escuela de Maestros de la Universidad Católica de Colombia (6 de junio de 2013).

** Abogado, magíster en filosofía y profesor de la Universidad Católica de Colombia. Correo electrónico: lacelyo@unal.edu.co 
Finally, on the basis of the foregoing, what is designated as "speculative carácter of peripheral iustheory" and some general conclusions will be presented.

\title{
Key words:
}

Production places, transnational theory of law, representation, hermeneutics, Diego Lopez, Gadamer.

\section{O CARÁTER ESPECULATIVO DA IUSTEORIA PERIFÉRICA}

\begin{abstract}
Resumo
Este artigo analisa a relação entre "lugares de produção" e "lugares recepção", da teoria jurídica proposta pelo professor Diego López (na Teoria impura do direito), através do conceito de "representação" de Gadamer em Verdade e método, para mostrar o potencial teórico (e a relevância) que tem a iusteoria periférica na leitura transnacional do pensamento jurídico. Primeiro, será exposto, o vínculo entre "lugares de produção" e "lugares de recepção" na teoria transnacional do direito que desenvolve López. Segundo, será realizada uma exposição do conceito de "representação" de Gadamer para propor o que ele denomina o "caráter especulativo da linguagem". Finalmente, se apresentará, a partir do anterior, o que se designa como o "caráter especulativo da iusteoria de periferia" e serão expostas umas conclusões gerais.
\end{abstract}

\section{Palavras chave:}

Lugares de produção, teoria transnacional do direito, representação, hermenêutica, Diego López, Gadamer.

\section{INTRODUCCIÓN}

Todo hablar humano es finito en el sentido de que en él yace

la infinitud de un sentido por desplegar e interpretar.

Gadamer, 1984, p. 549

La producción intelectual del mundo periférico ha sido habitualmente subvalorada. La iusteoría periférica se considera una pura imitación (o mala copia) que no tiene ningún valor en sí misma, no quedándole más remedio que asumir un papel pasivo que consiste en reproducir de la manera más fiel posible todos los productos e invenciones intelectuales de la teoría jurídica hegemónica. Los intentos por lograr algún tipo de originalidad de parte de los autores periféricos, han sido calificados como verdaderos barbarismos intelectuales ("barbarización del conocimiento"), producto de malas lecturas e incomprensiones que tergiversan el correcto sentido de los planteamientos teóricos de la tradición (López, 2012). Es así que, los autores periféricos, para que no sean marginados del debate transnacional, tienen que ajustarse constantemente a lo que establece la "lectura estándar" dada por el canon del pensamiento jurídico dominante (pensamiento fuerte/pensamiento único).

El presente artículo pretende brindar una propuesta que reivindique el papel que tiene la iusteoría periférica en el pensamiento jurídico transnacional. A través del concepto de "representación" gadameriano se intenta repensar la relación entre "sitios de producción" y "sitios de recepción" que sugiere Diego López, para mostrar la relevancia y los potenciales teóricos que tiene la teoría periférica para la lectura transnacional del derecho (sin que ello signifique optar por una 
especie de provincionalismo teórico o insinuar un rechazo incondicionado a la cultura transnacional del derecho). Lo que se procura mostrar (tesis) es que la teoría periférica constituye un enfoque provechoso para la producción y la creación del pensamiento jurídico; y que esa singularidad interpretativa y creativa que ostenta, está dada precisamente por su posición supuestamente pasiva frente a la tradición dominante. Dicho de otra forma -en clave gadameriana-: su potencial hermenéutico radica en su capacidad de representación. Para llevar a cabo el planteamiento, el artículo se abordará de la siguiente manera:

Primero, se desarrollará, en términos muy generales, la relación entre "sitios de producción" y "sitios de recepción" en la teoría transnacional del derecho propuesta por el profesor Diego López, en tanto que es el soporte conceptual desde el cual presentaremos las ideas para pensar la asociación entre centro y periferia. Segundo, se realizará una exposición del concepto de "representación" de Gadamer (1984) para dar a conocer lo que él denomina en Verdad y método como el "carácter especulativo del lenguaje". Por último, se presentará, a partir de lo anterior, lo que hemos nombrado como el "carácter especulativo de la iusteoría de periferia" y dar unas conclusiones generales.

\section{TEORÍA IMPURA DEL DERECHO DE DIEGO LÓPEZ}

\section{Influencia y transmutación entre los "sitios de producción" y los "sitios de recepción" de la teoría transnacional del derecho}

La propuesta de Diego López -tal y como Duncan Kennedy lo señala en el prólogo de la Teoría impura del derecho- "[...] ofrece un nuevo paradigma para explorar la relación entre [...] los 'sitios de producción' de teoría jurídica y los 'sitios de recepción de la misma"' ( Kennedy citado en Lopez, 2012, xi). A través de dicho vínculo se puede examinar los procesos de transmutación/ transformación que sufre la lectura estándar de la iusteoría transnacional, los cuales no solamente enriquecen (diversifican) las lecturas dominantes sino que alimentan y construyen -consciente o inconscientemente- la teoría jurídica popular ("teoría pop") con la que se reproducen las prácticas jurídicas en un ámbito local determinado. Frente al casi sacralizado supuesto universalista y abstracto de un gran discurso teórico-jurídico de alcance global, vendría a plantearse algo así como una pluralidad de campos y de teorías jurídicas heterogéneas. Las transmutaciones o "malas lecturas" no serían simples copias de la lectura estándar, puesto que, como dice López, "han impulsado prácticas jurídicas locales y, por lo tanto, están ya imbricadas con la cultura local produciendo dinámicas pasadas y futuras, que ya no se pueden deshacer [...]" (2012, p. $35)$, lo que ya, de por sí, las hace relevantes e interesantes para, al menos, la cultura jurídica local en donde se producen.

Pero, además, el proceso de transmutación (que implica la presencia de un canon de influencia fuerte, como la teoría transnacional o hegemónica, que produce el "aprisionamiento" teórico para, finalmente, llegar a la resolución del conflicto en la producción de teoría), es una característica esencial de toda práctica intelectual (y cultural), y por lo mismo, un signo del proceso constructivo de cualquier tradición (sea esta dominante o periférica), lo cual conlleva que dejemos de pensar la influencia (y la tardanza), la imitación y el mismo proceso de transmutación o transformación (tergiversación y la "mala lectura") como un aspecto negativo (López, 2012). Al contrario, la transmutación vendría a ser pensada como supuesto -conditio sine qua non-de todo proceso creativo y parte fundamental de cualquier producción intelectual y cultural.

Por otro lado, el planteamiento de López (2012) pone de manifiesto cómo, desde la creencia (o velo) de una supuesta fidelidad a la lectura estándar, las lecturas de los sitios de recepción responden a las condiciones, y a las aspiraciones predominantes de su ámbito local; lo que constituye toda una propuesta crítica, al menos para nuestro contexto jurídico, en tanto que hace evidente y revelador cómo influyen las circuns- 
tancias culturales y los imaginarios compartidos (Diego López se encuentra más cercano al modelo culturalista de la mutación eidética que al materialista e institucional) desde los cuales las teorías y las prácticas jurídicas, sean del centro $y$ especialmente las de periferia, interpretan y consolidan sus cánones y se reproducen más allá del supuesto legal-formalista de la retórica de la neutralidad, la coherencia y la racionalidad interna y universal del discurso jurídico -lo que Diego López denomina como "clasicismo"(Kennedy, 1999).

De tal forma, el proceso de transmutación entre sitios de producción y de recepción no solamente repercute en lo que son y cómo son las prácticas jurídicas locales, sino que, además de generar lecturas alternativas a la estándar, constata las tensiones y disputas que se generan en campos de periferia específicos. Así, muchas de las transformaciones teóricas son resultado de tergiversaciones $\mathrm{u}$ omisiones intencionadas de parte de los actores en un campo local determinado (de lecturas selectivas o enfatizadas). Por eso es que los cambios de sentido o significado de las lecturas estándar en los sitios de recepción bajo los procesos de transmutación, solamente adquieren coherencia y justificación cuando se estudian y comprenden en su contexto, en tanto que es ahí donde se puede detectar la serie de motivos y necesidades que lo hace transmutar. Desde esta óptica, López (2012) va a señalar que una tarea todavía no hecha por la ciencia del derecho periférica es dar cuenta de las dinámicas y procesos que llevaron al derecho local a ser lo que es (y lo que será), en vez de seguir girando en torno a la autorreferencialidad de la teoría dominante: "la labor científica de la iusfilosofía es explicar sistemas jurídicos concretos y no sistemas jurídicos abstractos" (López, 2012, p. 51).

\section{ASPECTOS RELEVANTES (CONCLUSIÓN PROVISIONAL)}

Serían cuatro los aspectos que, a manera de conclusión provisional y en relación con la teoría de
López (2012), consideramos resultan relevantes hasta aquí para el presente artículo:

Lo primero es que entre los sitios de producción y los sitios de recepción se genera una relación de influencia que no se agota en la simple copia o mala imitación.

Segundo, el proceso de transmutación, la tergiversación y la "mala lectura" no tienen un carácter esencialmente negativo sino que en realidad son formas potencialmente creativas para la construcción de la tradición jurídica local y transnacional. En otras palabras, la transmutación de las teorías enriquece y diversifica la serie de interpretaciones canónicas de la teoría transnacional.

Tercero, la relación de influencia permite constatar la existencia de una pluralidad de mundos jurídicos que resultan igual de sofisticados, interesantes y complejos que los de la tradición dominante, contrario a la idea de un mundo periférico puramente pasivo y simplón.

El cuarto aspecto es el ejercicio de resignificación de lo que entendemos por "tergiversaciones" y "malas lecturas", lo cual devela la complejidad del entramado teórico jurídico en el que se desenvuelve la tradición periférica más allá de la transnacional. Las "malas lecturas" no son simplemente resultado de un error debido a las carencias de los intérpretes en el contexto local, sino que obedecen a fines y tensiones ocultas que son muchas veces invisibles e incomprensibles para la perspectiva del mundo dominante.

Aunque para López (2012) resulte más importante explicar los sistemas jurídicos concretos, en este estudio es igualmente atrayente ver cómo todos estos aspectos en mención apuntan a reivindicar el papel que tiene la teoría jurídica de la periferia en el pensamiento jurídico global. Es decir, reconocer que hay un lugar muy particular e insustituible para el enfoque de la iusteoría periférica que no solo es relevante en el ámbito local, sino que también resulta sustancial para la construcción del pensamiento jurídico transnacional. 


\section{El carácter de representación del arte y el carácter especulativo del lenguaje en Gadamer}

\section{El carácter de representación en el arte}

Con la modernidad y las teorías estéticas del siglo XVIII se impone el concepto de expresión como categoría articuladora de la experiencia artística, desplazando al de representación (Gadamer, 1967). Más aún, el arte como imitación y representación queda reducido a una búsqueda por la semejanza o la copia de la naturaleza. Es así como el planteamiento de Platón en su crítica a los poetas adquiere todo sentido, pues el arte entendido de esta manera es reprochable en tanto se aleja de la verdad: la realidad es falseada en la imitación de la imitación (Gadamer, 1998). Por el contrario, Gadamer (1984) reinventa y actualiza la idea del arte como representación. Tal concepción de imitación es elaborada desde Aristóteles cuando se describe fenomenológicamente la intención del niño cuando se disfraza. El niño en la imitación busca representar lo representado, puesto que su intención no es que le vean tras el disfraz pero tampoco engañar con el disfraz, sino mostrar lo que está siendo representado a través de él mismo con el disfraz.

En el juego mimético no se crea nada real sino que se lleva algo a su representación, pero dicha representación lo que busca es mostrar lo representado: hacer algo visible de manera correcta, es decir, más allá de lo que la realidad ofrece como tal. Por esta razón es que Gadamer insiste varias veces en "El juego del arte" en la diferenciación entre la representación mímica y el engaño (simpatía hipócrita). Mientras que el engaño quiere ser creído, la imitación mímica no quiere ser creída sino entendida como imitación. Se muestra como apariencia y quiere ser percibida como apariencia, Gadamer (1998) la denomina como "apariencia verdadera", puesto que en tanto apariencia es que se permite mostrar algo (Gadamer, 1998). Lo "que se hace visible en la imitación es, precisamente, la esencia más propia de la cosa" (Gadamer, 1998, p. 88).
Ya en la teoría de las formas de Platón podemos hallar la clave para comprender el carácter de representación en el arte (Gadamer, 1984): aunque lo bello y lo bueno se identifiquen en su calidad de fin en sí mismo (y no como simple medio-útil), encuentran una distinción definitiva que determina el predominio de lo bello sobre lo bueno: "[en] la esencia de lo bello está el que se manifieste" (Gadamer, 1984, p. 575). Lo que le es más característico a lo bello está en que se muestra por sí solo o, en otras palabras, en su representarse (cosa que no ocurre con lo bueno). Así lo bello tiene luz propia (tiene el modo de ser de la luz): no es lo que ilumina sino que es el iluminar mismo lo que hace patente lo bello. De tal forma que su manera de ser está en su modo de aparecer y hacer aparecer algo. Según Gadamer (1984) el relato de la creación de Agustín es aclarador al respecto, puesto que la creación de la luz - "hágase la luz"- permite darle forma a las cosas y hace comprensible el mundo. "Por lo tanto el 'aparecer' no es solo una propiedad de lo que es bello, sino que es lo que constituye su verdadera esencia" (Gadamer, 1984, p. 576).

Es el carácter de representación de toda esta "metafísica de la luz" lo que nos permite entender el sentido de la obra de arte. Lo bello se representa en su iluminar mismo pero a la vez ilumina lo otro (lo bueno), que en tanto lo representado no le es distinto sino que es precisamente en su representación donde se da su modo de ser más verdadero. "No es el resplandor vertido sobre la forma y que accede a ella desde afuera. Al contrario, la constitución óntica misma de esta forma es brillar así, representarse asî" (Gadamer, 1984, p. 582). Lo que aparece por la luz no es distinto de como se muestra en la luz, sino que ese modo de mostrarse forma parte de su propio ser.

\section{El carácter especulativo del lenguaje}

El carácter de representación propio en el juego del arte se constata en el carácter especulativo que le es inherente al juego del lenguaje (véase cómo en el alemán spielen puede tener estos diferentes sentidos: jugar, representar e interpretar). 
Lo especulativo "hay que pensarlo como una relación refleja en lo que lo que se refleja es, por su parte, pura apariencia de lo reflejado, igual que lo uno es lo uno de lo otro y lo otro de lo uno" (Gadamer, 1984, p. 558). La relación es de referencia en lo otro pero no es más que la existencia de uno solo. En la reflexión lo reflejado no es distinto de lo que se refleja, pero, a su vez, en tanto pura apariencia, guarda una distinción (piénsese, por ejemplo, en la relación refleja frente a un espejo).

El lenguaje tiene un carácter especulativo en tanto que es apariencia de lo que se refleja. Es el modo de ser de lo reflejado, sin que esto implique ser una mera copia o una duplicación distinta a lo reflejado en el reflejo. El lenguaje al igual que lo bello se hace patente en su aparecer mismo. Lo que accede al lenguaje no es distinto a como aparece en el lenguaje sino que su apariencia le es propia en su ser. "Por lo tanto en todo aquello que es lenguaje se trata de una unidad especulativa, de una distinción en sí mismo: ser y representarse, una distinción que, sin embargo, tiene que ser al mismo tiempo una indistinción" (Gadamer, 1984, p. 568).

Por eso mismo, la "forma lingüística y el contenido [y sentido] transmitido no pueden separarse en la experiencia hermenéutica" (Gadamer, 1984, p. 529). No hay un mundo prelingüístico, tal y como lo intuye Humboldt, pero tampoco un lenguaje sin mundo (ni tradición). Lo que es "en sí" no está más allá de su representación (apariencia) en el lenguaje. La determinación (finitud), a través de lo representado, es la manera en que aparece la totalidad y es el modo de ser de la infinitud; mientras que, en tanto el lenguaje tiene un carácter especulativo, lo uno que se muestra siempre le pertenece ya a lo que le interpela en la tradición (hermenéutica de la pregunta). La representación (aparece) no es algo distinto a lo representado sino su verdadero modo de ser. La distinción y su indistinción acontecen en un mismo momento: en el lenguaje (Grondin, 2003).

Por otro lado, en la determinación temporal del lenguaje como acontecer (al respecto véase el fenómeno de la "fiesta") se convoca el sentido de la totalidad (infinitud) en lo uno: se hace patente lo no dicho. El lenguaje en tanto determinación finita en el acontecer (evento/representación) convoca al sentido pero lo retiene a la vez. La experiencia hermenéutica de nuestra finitud es manifiesta a través de la palabra que nos posibilita el reconocernos en la familiaridad de un mundo al cual pertenece y su sentido, pero que alude igualmente a la extrañeza que produce un mundo que se nos sustrae en lo no dicho y en lo que puede decir. "Todo hablar humano es finito en el sentido de que en él yace la infinitud de un sentido por desplegar e interpretar" (Gadamer, 1984, p. 549). Así

[...] nos movamos en el lenguaje que nos movamos, nunca llegamos a otra cosa que a un aspecto cada vez más amplio, a una "acepción" del mundo [...] lo que el mundo es no es nada distinto de las acepciones en las que se ofrece (Gadamer, 1984, p. 536).

Es decir, al lenguaje mismo. A una representación. $\mathrm{El}$ "ser es lenguaje, esto es, representarse" (Gadamer, 1984, p. 581) -ontología hermenéutica-. No hay un mundo que tenga una existencia autónoma frente al lenguaje y el lenguaje solo existe en la representación del mundo. Como ocurre con lo bello que tiene su modo de ser en el aparecer. Como decíamos: lo que aparece por la luz no es distinto de como se muestra en la luz, sino que ese modo de mostrarse forma parte de su propio ser (legitimación de la apariencia real). "Es en el lenguaje donde se hace claro lo que es real más allá de la conciencia de cada uno" (Gadamer, 1984, p. 538).

\section{ASPECTOS RELEVANTES (CONCLUSIONES PROVISIONALES)}

Podemos sintetizar cinco aspectos clave del planteamiento gadameriano en cuanto al carácter especulativo del lenguaje para el presente estudio:

El primero es la reinvención que Gadamer (1984) hace de la idea del arte como imitación 
que no se agota en la pura copia, sino que en tanto representación hace algo visible de manera correcta, es decir, más allá de lo que es representado -este aspecto es parecido al que planteábamos en relación con López (2012) en la sección anterior-.

El segundo, es la tensión que se genera a partir de la reflexión, en tanto que lo reflejado y lo que se refleja son uno solo, pero, a su vez, son distintos (el primero como el segundo aspecto, vendrían a ser propios del lenguaje en cuanto su carácter especulativo).

Un tercer elemento muy importante es la actualidad como la determinación temporal propia del lenguaje. Este rasgo nos descubre que el lenguaje tiene un carácter inherentemente finito. Esto significa que siempre en lo dicho hay algo no dicho y también algo por decir.

Un cuarto aspecto sería el sentido de pertenencia a la tradición a través del lenguaje y cómo a su vez la tradición es representada en la actualidad del lenguaje (sentido medial).

Y por último, la idea de diversas acepciones de mundo y que el mundo no es nada distinto a esas acepciones en las que se nos ofrece.

\section{El carácter especulativo \\ de la teoría periférica: apariencia verdadera}

La idea que proponemos aquí es que pensemos a la iusteoría periférica desde el concepto gadameriano de "representación" en relación con la teoría transnacional del derecho. En otras palabras, que planteemos la relación entre los "sitios de producción" y los "sitios de recepción" jurídica como una relación refleja, en la cual la perspectiva periférica vendría a ser una representación de la tradición dominante que no se agota en lo representado.

Esto sería lo que, en términos hermenéuticos, podríamos denominar como una superación del modelo metafísico de la teoría y la historia de las ideas del derecho. La teoría transnacional del derecho parece partir de una concepción lineal, sucesiva y acumulativa del tiempo, en tanto que no hay posibilidad de darse desde ese tiempo un retorno al futuro del pasado. No permite en muchos casos generar una apertura interpretativa de lo dicho y lo pensado en tanto que supone que los pasados ya están muertos. Pensemos, por ejemplo, la idea de "tardanza": lo dicho en el pasado se encuentra clausurado y aquel que llega tarde a lo ya dicho siempre se encuentra ante una realidad agotada. Lo único que se puede y queda por hacer es reproducir fielmente el canon para no tergiversarle. Es así que la "investigación tardía" adquiere un sentido negativo, puesto que no existe posibilidad alguna de instaurar otras formas de memoria (interpretación) que se hagan cargo de ese pasado (López, 2012). Esto, por cierto, termina convirtiéndose en una lógica altamente violenta, ya que no permite reconocer diferencias y alternativas a la lectura estándar; por el contrario, opera haciendo invisible y reprimiendo todo aquello que no se adecúe al pensamiento dominante (único).

La racionalidad hermenéutica, en cambio, parte de una concepción transhistórica de la memoria, lo que significa que no se limita a la comprensión cronológica y sucesiva del tiempo en la cual el pasado está ya clausurado, sino que piensa el pasado como algo vivo y en constante transformación (como potencia). Al igual que la obra de arte (por eso es el paradigma del pensamiento hermenéutico), el pasado no se agota en sus múltiples interpretaciones, sino que es a partir de esas determinaciones donde acontece y se convoca lo no dicho como un sentido por desplegar. La iusteoría periférica, desde esta perspectiva, vendría no solamente a constituirse en una manera en donde acontece y se convoca el sentido de lo dicho, sino, y más radical aún, que entraría a ser el lugar de lo no pensado en lo dicho. Un sentido por desplegar.

La iusteoría periférica tiene un carácter especulativo. Como en Gadamer (1984) respecto al lenguaje, podríamos sugerir la relación entre "sitios de producción" y " sitios de recepción" como una relación refleja. No es que exista una 
lectura real o correcta a la cual accedemos, sino que tal y como accedemos a esa lectura es la manera como esta acontece (acepciones jurídicas). Es, según decíamos frente al lenguaje, un modo de su propio ser. Esto sería lo que produce la tensión reflexiva: no es distinto lo que se refleja de lo reflejado puesto que es un modo de su propio ser, pero en tanto apariencia (representación) de lo reflejado, guarda una distinción. Por un lado, el reflejo es un modo de ser de lo reflejado que no se reduce a una pura copia, sino que en tanto reflejo es que se permite mostrar algo más allá de lo reflejado (distinción); pero, por otro lado, eso que es reflejado no es distinto de su reflejo, puesto que esa determinación le es propia en su ser (indistinción). De esta forma, podríamos decir que entre los sitios de producción y los sitios de recepción existe una unidad especulativa (son una distinción en sí misma). Eso que llamamos la "lectura estándar" no sería algo diferente a como es representada (interpretada) en las lecturas periféricas. No hay una lectura que tenga una existencia independiente a la manera como es representada (interpretada), sino que su interpretación no es otra cosa que un aspecto más amplio de cómo acontece. Una representación.

La iusteoría periférica como representación tiene un potencial hermenéutico muy valioso e insustituible en tanto que hace algo visible más allá de lo que es representado. En otras palabras, la iusteoría periférica puede mostrar lo que la teoría transnacional del derecho no puede. No se trata de una pura imitación o "mala lectura" como generalmente se cree. Tal y como mostrábamos con el ejemplo del niño que se disfraza: la representación nos está haciendo visible un rasgo o aspecto de lo representado que por sí mismo no puede advertirse. Por ejemplo, la representación de un hecho histórico en una obra de teatro o la ilustración de un paisaje. Puede que efectivamente hayamos estado ahí, pero solamente advertimos o se nos hace manifiesto ese lugar y ese momento cuando la representación nos lo muestra. La representación hace visible aquello que no podría ser advertido de otra manera.
Cuando decimos que la teoría periférica tiene un carácter especulativo puede entenderse también en este sentido, puesto que en su capacidad de representación permite desplegar sentidos diferentes a los efectivamente ya pensados. Aún más, es precisamente ese carácter periférico el que le da una singularidad interpretativa que no puede sustituirse por ninguna otra. La perspectiva de la teoría periférica resulta siendo relevante e imprescindible para el pensamiento jurídico, porque puede decir lo no dicho por la teoría transnacional del derecho (el "punto ciego" de la teoría transnacional y su carácter finito): su potencial hermenéutico radica en su capacidad de representación.

\section{CONCLUSIONES}

Contrario a la creencia generalizada, la teoría periférica posee una singularidad interpretativa que la hace importante para el pensamiento jurídico transnacional (hasta para su propia comprensión). La racionalidad hermenéutica planteada desde el carácter especulativo de la iusteoría periférica, permite reivindicar, en principio, el papel creativo que esta desempeña en la producción intelectual y cultural para el pensamiento jurídico dominante.

La iusteoría periférica como representación, según las reflexiones que se esbozaron, debe entenderse como una alternativa metodológica que nos ayuda a repensar la relación de centro y periferia a partir del "pensamiento débil"; constituyéndose, como decíamos, en el "punto ciego" de la teoría transnacional, lo que la hace no solamente insustituible sino que además radicalmente sugestiva en términos hermenéuticos por su singularidad interpretativa.

De todas formas, queda entonces la tarea de ver los alcances que puede tener esta perspectiva para la comprensión del derecho y las posibilidades críticas que desde aquí se pueden desprender. 
No obstante, haría falta pensar la relevancia práctica del carácter especulativo de la teoría periférica a partir de casos concretos (ejemplos), lo cual amerita futuras exploraciones al respecto que por su singularidad y profundidad rebasan las expectativas del presente artículo.

\section{REFERENCIAS}

Gadamer, H. (1998). Oír-ver-leer. En: Arte y verdad de la palabra. Barcelona: Paidós. Recuperado de http://www.bibliotecah.org.uy/escribir/ biblio/oirverleer.pdf

Gadamer, H. (1984). Verdad y método. Fundamentos de una hermenéutica filosófica. Salamanca: Sígueme.
Gadamer, H. (1998). Arte e imitación. En: Estética y hermenéutica. Madrid: Tecnos.

Grondin, J. (2003). Introducción a Gadamer. Barcelona: Herder.

Kennedy, D. (1999). Libertad y restricción en la decisión judicial. Bogotá: Siglo de Hombre.

López, D. (2012). Teoría impura del derecho. La transformación de la cultura jurídica. Bogotá: Legis. 